\title{
MICROSTRUCTURAL COMPARISON OF HT-9 IRRADIATED IN HFIR AND EBR-II
}




\section{DISCLAIMER}

This report was prepared as an account of work sponsored by an agency of the United States Government. Neither the United States Government nor any agency Thereof, nor any of their employees, makes any warranty, express or implied, or assumes any legal liability or responsibility for the accuracy, completeness, or usefulness of any information, apparatus, product, or process disclosed, or represents that its use would not infringe privately owned rights. Reference herein to any specific commercial product, process, or service by trade name, trademark, manufacturer, or otherwise does not necessarily constitute or imply its endorsement, recommendation, or favoring by the United States Government or any agency thereof. The views and opinions of authors expressed herein do not necessarily state or reflect those of the United States Government or any agency thereof. 


\section{DISCLAIMER}

Portions of this document may be illegible in electronic image products. Images are produced from the best available original document. 
Operated by

Westinghouse

Hanford Company

A Subsidiary of

for the U.S. DOE

Westinghouse Electric

Corperation

Contract No.

P.D. Box 1970

DE-AC06-76FF02170

Richland, WA 99352

\section{Hanford Engineering Development Laboratory}

\section{INFORMATION CONCERNING USE OF THIS DOCUMENT}

\section{NOTICE}

This report was prepared as an account of work sponsored by an agency of the United States Government. Neither the United States Government nor any agency thereof, nor any of their employes, nor any of their contractors, subcontractors or their employes, makes any warranty, express or implied, or assumes any legal liability or responsibility for the accuracy, completeness, or any third party's use or the result of such use of any information, apparatus, product, or process disclosed, or represents that its use would not infringe privately owned rights. Reference herein to any specific commercial product, process, or service by trade name, trademark, manufacturer, or otherwise, does not necessarily constitute or imply its endorsement, recommendation, or favoring by the United States Government or any agency thereof or its contractors or subcontractors. 
HEDL-7543

\title{
MICROSTRUCTURAL COMPARISON OF HT-9 IRRADIATED IN HFIR AND EBR-II
}

\author{
D.S. Gelles \\ Date Published: May 1985
}

\section{DISCLAIMER}

This report was prepared as an account of work sponsored by an agency of the United States Government. Neither the United States Government nor any agency thereof, nor any of their employees, makes any warranty, express or implied, or assumes any legal liability or responsibility for the accuracy, completeness, or usefulness of any information, apparatus, product, or process disclosed, or represents that its use would not infringe privately owned rights. Reference herein to any specific commercial product, process, or service by trade name, trademark, manufacturer, or otherwise does not necessarily constitute or imply its endorsement, recommendation, or favoring by the United States Government or any agency thereof. The views and opinions of authors expressed herein do not necessarily state or reflect those of the United States Government or any agency thereof.

HANFORD ENGINEERING DEVELOPMENT LABORATORY - Operated by Westinghouse Hanford Company, P.O. BOX 1970, Richland, WA, a Subsidiary of Westinghouse Electric Corporation. Prepared for the USDOE, Office of Energy Research, Office of Fusion Energy, under Contract No. DE-AC06-76FF02170, B\&R No. AT-15-02-03-04. 
MICROSTRUCTURAL COMPARISON OF HT-9 IRRADIATED IN HFIR AND EBR-II

D. S. Gelles

Westinghouse Hanford Company

A series of specimens of HT-9 heat 91354 have been examined following irradiation in HFIR to $39 \mathrm{dpa}$ at $300,400,500$ and $600^{\circ} \mathrm{C}$ and following irradiation in EBR-II to $29 \mathrm{dpa}$ at 390 and $500^{\circ} \mathrm{C}$. HFIR irradiation was found to have promoted helium bubble formation at all temperatures and voids at $400^{\circ} \mathrm{C}$. Cavitation had not been observed at lower fluence, nor was it found in EBR-II irradiated specimens. The onset of void swelling in HFIR is attributed to helium generation. The observations provide an explanation for saturation of ductile-brittle transition temperature shifts with increasing fluence. 
7.9 MICROSTRUCTURAL COMPARISON OF HT-9 IRRADIATED IN HFIR AND EBR-II - D. S. Gelles (Westinghouse Hanford Company)

\subsubsection{ADIP Task}

The Department of Energy (DOE)/Office of Fusion Energy (OFE) has cited the need to investigate ferritic alloys under the ADIP program task, Ferritic Steels Development (Path E). The tasks involved are ak in to task number 1.C.2, Microstructures and Swelling in Austenitic Alloys and task number 1.C.1, Microstructural Stability.

\section{9 .2 objective}

The objective of this work is to provide guidance on the applicability of martensitic stainless steels for fusion reactor structural materials.

\subsubsection{Summary}

A series of specimens of HT-9 heat 91354 have been examined following irradiation in HFIR to 39 dpa at $300,400,500$ and $600^{\circ} \mathrm{C}$ and following irradiation in EBR-II to 29 dpa at 390 and $500^{\circ} \mathrm{C}$. In most cases, identical specimens had been previously examined following irradiation to lower dose.

HFIR irradiation was found to have promoted helium bubble formation at all temperatures and voids at $400^{\circ} \mathrm{C}$. Helium bubbles were generally associated with subgrain boundaries or dislocations within grains. Void development was typical of the swelling incubation regime. Swelling had not been observed at lower fluence, nor was it found in EBR-II irradiated specimens. The onset of void swelling in HFIR is attributed to helium generation.

The major effect of increasing dose was found to be minor growth of dislocation loops and precipitate particles. All major microstructural features which were present at lower dose were retained. These observations provide an explanation for saturation of ductile-brittle transition temperature shifts with increasing fluence.

\subsubsection{Progress and Status}

\subsubsection{Introduction}

Following irradiation in HFIR at $400^{\circ} \mathrm{C}$ to $39 \mathrm{dpa}$, HT-9 heat XAA3587 was found to have developed void swelling. The swelling was very $10 \mathrm{w}, 0.07 \%$, consisting of $16 \mathrm{~nm}$ average diameter cavities at densities on the order of $3 \times 10^{20} / \mathrm{m}^{3}$ distributed non-uniformly. This represented an unusual observation of swelling in HT-9 because examination of HT-9 irradiated in EBR-II to 72 dpa showed no tendency for void swelling. 2 The swelling observed in the HFIR irradiated specimens was attributed "to a large extent to the helium produced during irradiation in HFIR." 1 However, an alternate explanation for the observation of swelling in HT-9 was proposed based on the absence of G-phase precipitation in these specimens ${ }^{3}$ under the assumption that the presence of G-phase in irradiated HT-9 suppressed void formation. ${ }^{4}$ Micrographs of HT-9 heat XAA3587 which contained voids showed no evidence of precipitation and results for heat XAA3587 were not available following irradiation in an environment where helium generation rates were lower, such as EBR-II. Therefore, a second variable, heat-to-heat variation, could explain the results. Note that a heat-to-heat variation in the swelling resistance of HT-9 could significantly affect the applicability of HT-9 for fusion reactor applications. It was therefore considered very important to determine if swelling in HT-9 was due to helium generation or composition variations.

The HFIR-CTR-30, -31 and -32 tests did contain several transmission electron microscopy (TEM) disk specimens of HT-9 heat $91354^{5}$ which had been irradiated in the same capsules as had specimens of heat XAA3587. As this heat was identical to that used in the AD2 test irradiated to $29 \mathrm{dpa}\left(6 \times 10^{22} \mathrm{n} / \mathrm{cm}^{2}\right)$ it was possible to determine the effect of helium generation without introducing heat-to-heat variables. Unfortunately, most of the disks were needed for disk bend ductility tests but one disk from each condition was made available for TEM examination. The present effort therefore centers on the examination of specimens of HT-9 heat 91354 irradiated in HFIR at $300,400,500$ and $600^{\circ} \mathrm{C}$ to $39 \mathrm{dpa}$ For comparison, specimens of HT-9 heat 91354 irradiated in EBR-II at 390 and $500^{\circ} \mathrm{C}$ to $29 \mathrm{dpa}\left(6 \times 10^{22} \mathrm{n} / \mathrm{cm}^{2}\right)$ were aTso examined. The results show that HT-9 does indeed swell in HFIR but not in EBR-II. Therefore, heat-to-heat variations are not responsible for this difference in behavior supporting the contention that helium encourages void formation in HT-9.

\subsubsection{Experimental Procedure}

Specimens selected for examination are listed in Table 7.9.1, along with corresponding irradiation conditions. All conditions were from the same heat of material, heat 91354 but heat treatments for the different irradiation tests were performed at different laboratories, at ORNL for the HFIR-CTR-30 test and at WHC for the EBR-II AD-2 teșt. Specimens irradiated in both tests had been examined following earlier discharges, $10 \mathrm{dpa}$ for $\mathrm{CTR}-32^{5}$ and $13 \mathrm{dpa}$ for AD-2. Experimental procedures in the present study were identical to those in the previous studies except that transmission electron microscopy has been performed only on thin foil specimens and the electron microscope used was a JEOL 1200 EX operating at $120 \mathrm{KeV}$. 
Table 7.9.1. Specimen conditions of HT-9 heat 91354 selected for microstructural examination. HFIR-CTR-30 fluences were estimated from reference 6 assuming a midplane position.

\begin{tabular}{llll}
$\begin{array}{l}\text { Identification } \\
\text { Code }\end{array}$ & $\begin{array}{l}\text { Irradiation } \\
\text { Experiment }\end{array}$ & $\begin{array}{c}\text { Fluence } \\
\text { dpa }\left(10^{22} \mathrm{n} / \mathrm{cm}^{2}\right)\end{array}$ & Temperature \\
\hline SA24 & HFIR-CTR-30 & $39(19.5)$ & $300^{\circ} \mathrm{C}$ \\
SA21 & HFIR-CTR-30 & $39(19.5)$ & $400^{\circ} \mathrm{C}$ \\
SA23 & HFIR-CTR-30 & $39(19.5)$ & $500^{\circ} \mathrm{C}$ \\
SA22 & HFIR-CTR-30 & $39(19.5)$ & $600^{\circ} \mathrm{C}$ \\
$2 H C P$ & EBRII-AD-2 & $29(6.1)^{*}$ & $390^{\circ} \mathrm{C}$ \\
$2 H C U$ & EBRII-AD-2 & $29(6.1)^{*}$ & $500^{\circ} \mathrm{C}$
\end{tabular}

*E>0.1 MeV, others E TOTAL

\section{9 .4 .3 Results}

HFIR-CTR-30

Specimens of HT-9 heat 91354 irradiated to 39 dpa in HFIR were found to retain the carbide and subgrain structure which was generated prior to irradiation and retained following irradiation at 300 and $400^{\circ} \mathrm{C}$ to $10 \mathrm{dpa} .^{5}$ Carbides were large and equiaxed but were not associated with martensite lath structure (lath structure was not found). Also, dislocation and precipitate structures which had been found following irradiation at 300 and $400^{\circ} \mathrm{C}$ to $10 \mathrm{dpa}$ were retained al though growth had occurred. However, a major difference could be identified due to irradiation to higher fluence. HT- 9 heat 91354 following irradiation at $400^{\circ} \mathrm{C}$ was found to contain a non-uniform distribution of faceted cavities at low density (typical of a material in the incubation regime for void swelling), and a higher density of smaller spherical cavities, most prominent at grain boundaries, but also uniformiy distributed through the grains (typical of helium bubbles). Specimens irradiated at 500 and $600^{\circ} \mathrm{C}$ were found to contain larger spherical cavities on grain boundaries and on dislocations within grains (again typical of helium bubble

development). The specimen irradiated at $300^{\circ} \mathrm{C}$ also showed features which were probably helium bubbles. $\mathrm{A}$ fine mottled appearance was found which in the under-focused imaging condition appeared to be small bubbles.

Examples of these structures are shown in Figures 7.9.1 through 7.9.3. Figure 7.9.1 shows low magnification examples of each' of the specimens examined. The large carbides which can be seen and the lack of martensite lath structure are characteristic of these specimens. It may be noted that irradiation at 500 and $600^{\circ} \mathrm{C}$ promotes the formation of subgrains and that subgrains which developed at $600^{\circ} \mathrm{C}$ contain very few dislocations. Careful examination of Figure $7.9 .1 \mathrm{~b}$ reveals that after irradiation at $400^{\circ} \mathrm{C}$, $\$ \mathrm{mall}$ voids and precipitate particles are present.

Figure 7.9 .2 provides examples of these microstructures at higher magnification. Figure $7.9 .2 a$ shows dislocation and precipitate structures in specimen $\$ A 24$ irradiated at $300^{\circ} \mathrm{C}$ to 39 dpa, the region on the left in dislocation contrast and the region on the right showing the presence of a fine array of $4 \mathrm{~nm}$ particles. Dislocation loops can be identified that are as large as $13 \mathrm{~nm}$ in diameter. Therefore, by comparison with previous results, ${ }^{5}$ it can be concluded that both dislocation loops and G-phase precipitate particles have approximately doubled in size when the irradiation dose was increased from 6 dpa to 36 dpa.

Figure $7.9 .2 \mathrm{~b}$ shows similar features for specimen $S A 21$ irradiated at $400^{\circ} \mathrm{C}$ to 39 dpa. The dislocation structure consists of dislocation tangles and perfect dislocation loops. The loops are as large as $33 \mathrm{~nm}$ and are predominantiy of type a<100v. The region on the right of Figure 7.9.2b contains a number of faceted cavities typical of higher void swelling regions in this specimen. However, careful examination of this micrograph reveals the presence of a large number of much smaller spherical cavities typical of helium bubbles or very small voids. Precipitate particles are randomly arrayed and as large as 30 nm although most are smaller. In comparison, irradiation to 10 dpa resulted in $8.0 \mathrm{~nm}$ particles often in 7 inear arrays. Therefore, it can be concluded that continued irradiation results in coarsening of the G-phase and loss of evidence for heterogeneous nucleation on dislocations.

Figures 7.9.2C and $d$, showing specimens SA23 and $5 A 22$ irradiated at 500 and $600^{\circ} \mathrm{C}$ to $39 \mathrm{dpa}$, appear simjlar. Subgrain boundaries are well defined and spherical cavities can be identified decorating boundaries and within grains, often clearly associated with dislocations which are weakly imaged. The major differences between these conditions are 1) the cavity size and distribution, and 2) the presence of precipitates with in subgrains after irradiation at $500^{\circ} \mathrm{C}$. Cavities after irradiation at $500^{\circ} \mathrm{C}$ are as 1 arge as $4 \mathrm{~nm}$ whereas after irradiation at $600^{\circ} \mathrm{C}$ the cavities are as large as $10 \mathrm{~nm}$. In all cases, they appear to be helium bubbles. The precipitate particles found following irradiation at $500^{\circ} \mathrm{C}$ could only be inaged in matrix dark field contrast and therefore the particles are identified as $\alpha^{\prime}$. 


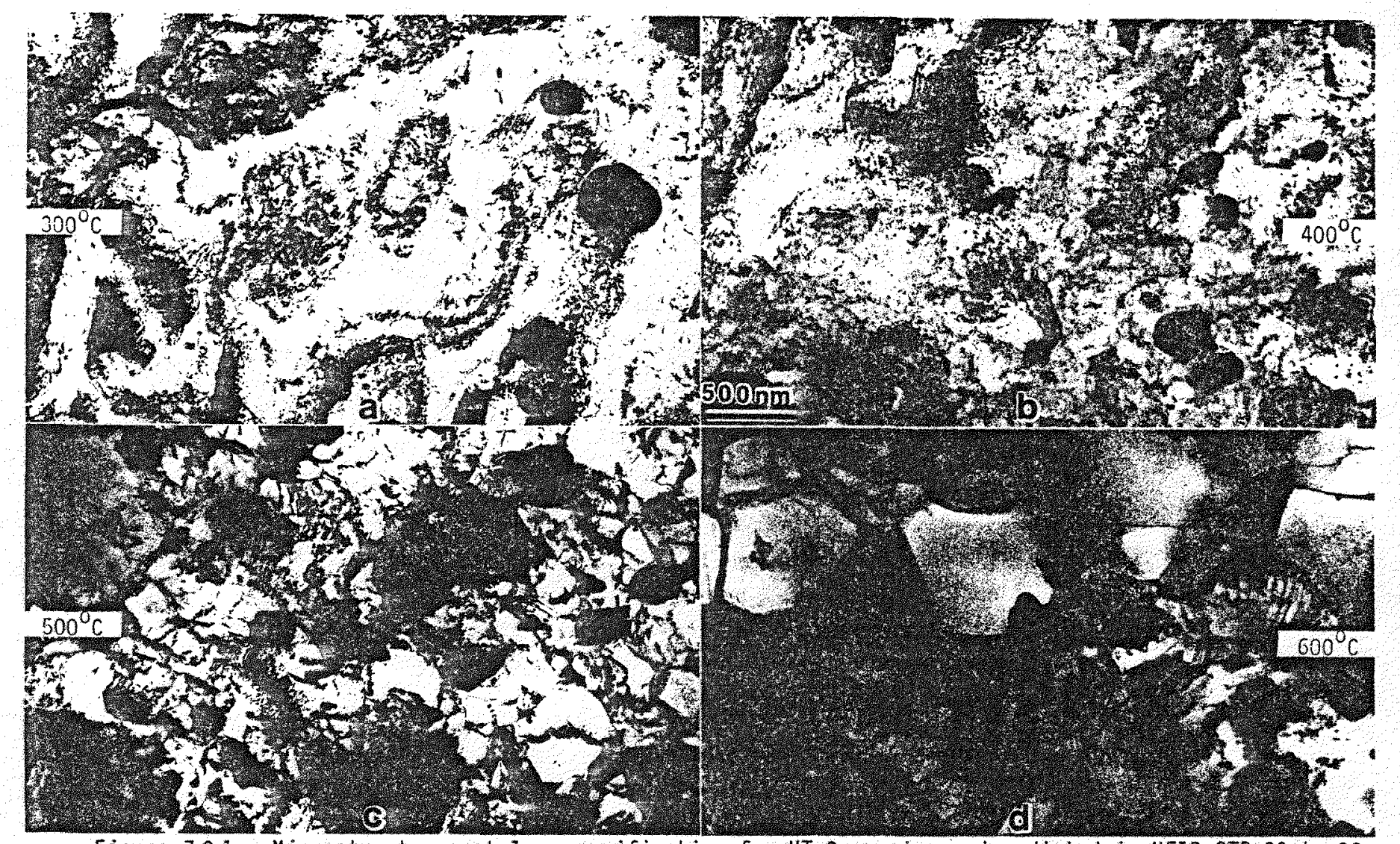

Figure 7.9.1. Microstructures at low magnification for HT-9 specimens irradiated in HFIR-CTR-30 to 39 dpa.

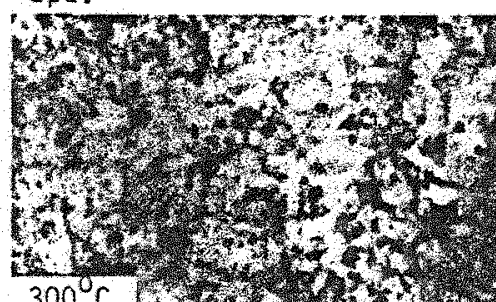

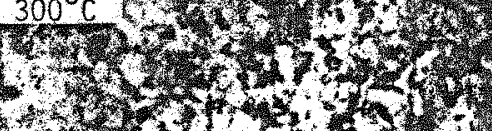

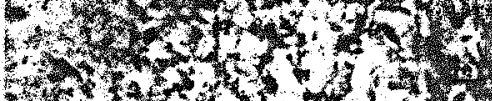

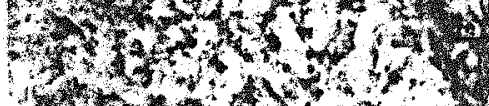

3.t.
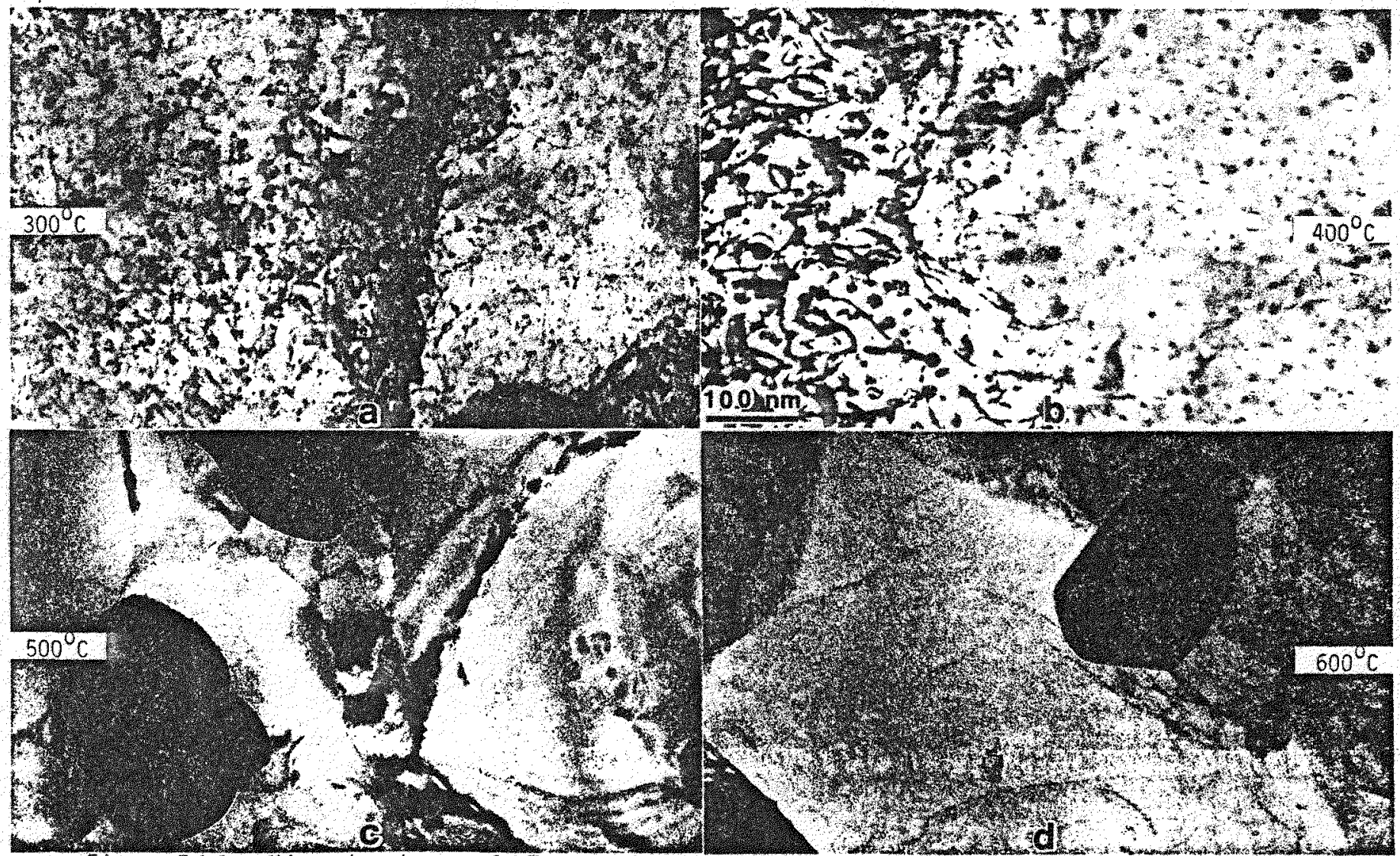

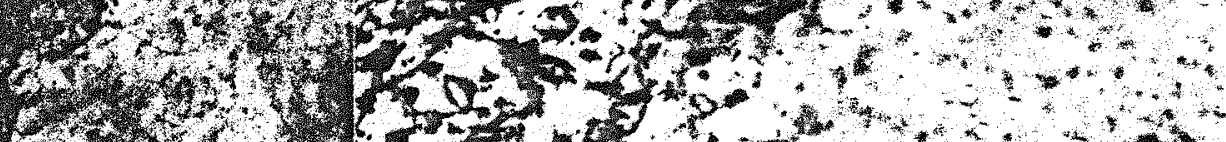

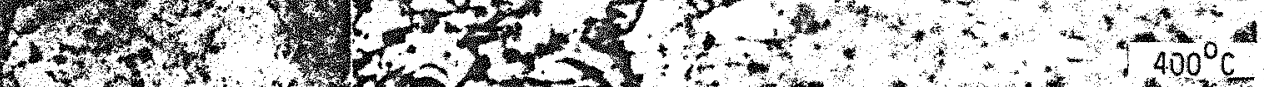

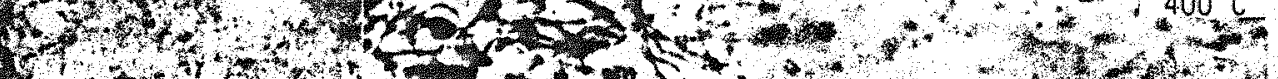

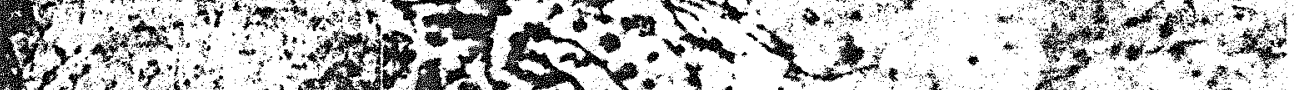

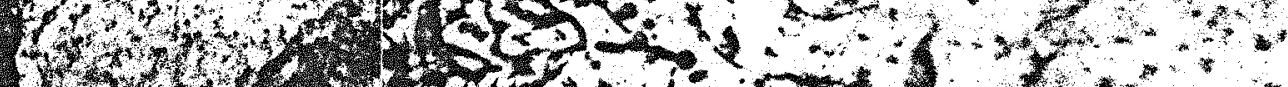

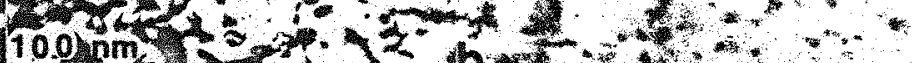

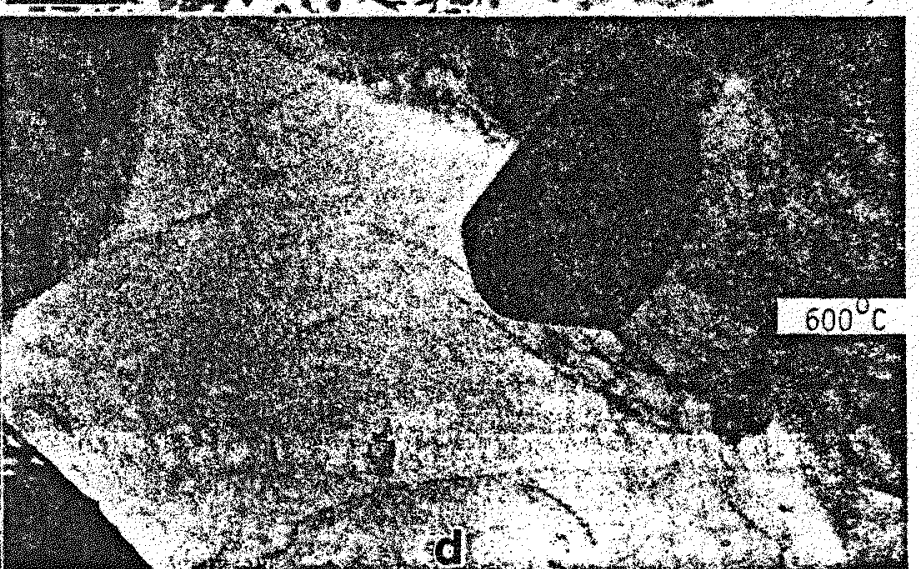
dislocation, precipitate and cavity structures. 
In order to show the fine structure found in the specimens of HT-9 heat 91354 , higher magnification micrographs are given in Figure 7.9 .3 for greater clarity. Figure 7.9.3a provides an example of the mottled structure found in specimen $\$ A 24$ irradiated at $300^{\circ} \mathrm{C}$. Note that a well developed subgrain boundary runs diagonally across the micrograph. If the structure is due to helium bubbles the bubbles are no more than $1.6 \mathrm{~nm}$ in diameter. Examples of helium bubbles on subgrain boundaries can be found in each of Figure $7.9 .3 b, c$ and $d$. It is apparent that bubble formation at grain boundaries is very non-uniform and is presumably associated with grain boundary dislocations.

of further note was the observation that substructure was developing in carbide particles due to irradiation. In order to show the range of response found, examples of carbide particles on the edge of foils which had been irradiated at $300^{2}$ and $600^{\circ} \mathrm{C}$ are shown in Figure 7.9.4. From Figure 7.9 .4 it is apparent that substructure in the form of a second phase, or dislocation loop structure has evolved. is uniikely that the structure is due to cavitation.) The structure is on the order of $3 \mathrm{~nm}$ after

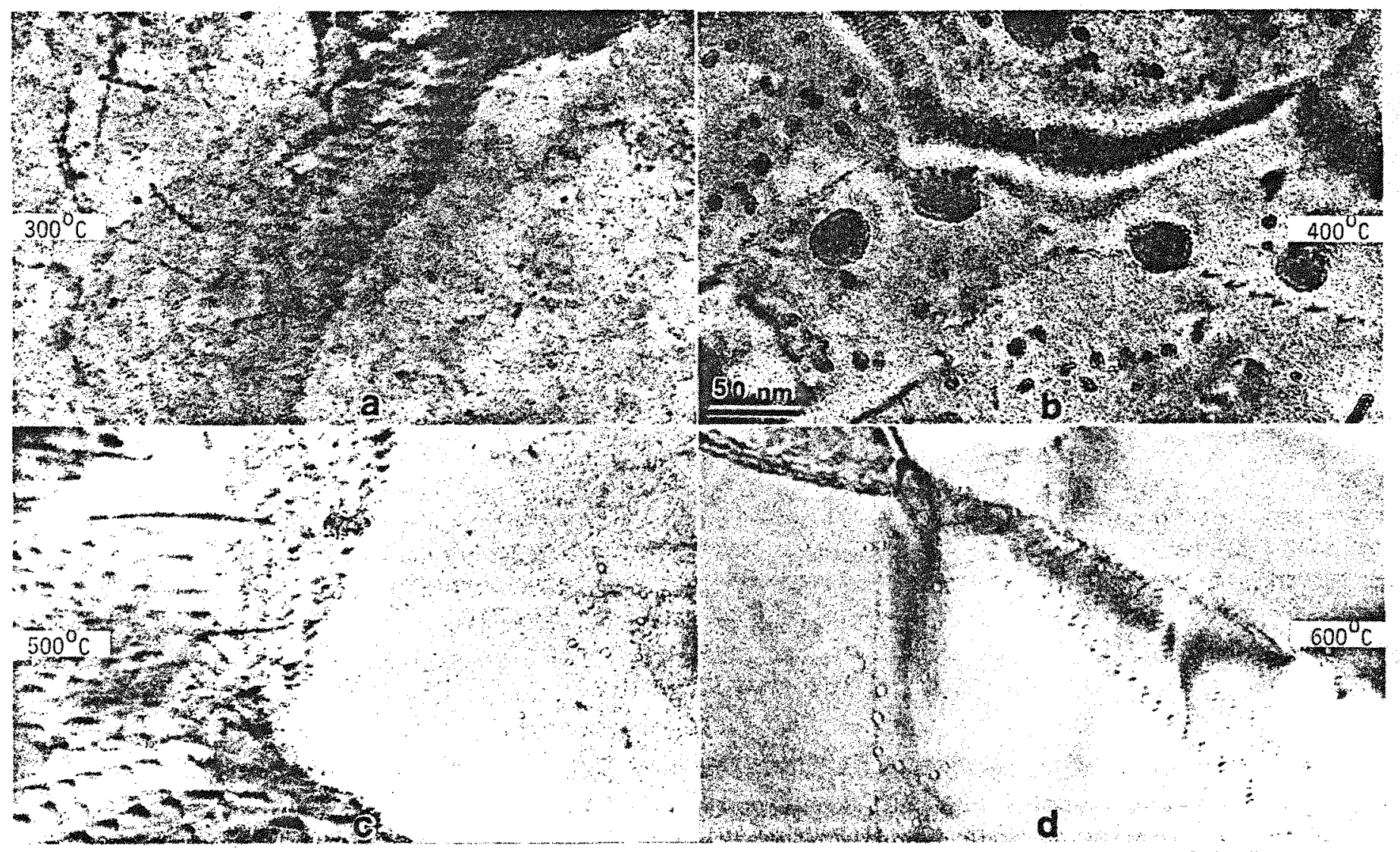

Figure 7.9.3. Microstructures at high magnification for HT-9 specimens irradiated in HFIR-CTR-30 showing helium bubble structure.

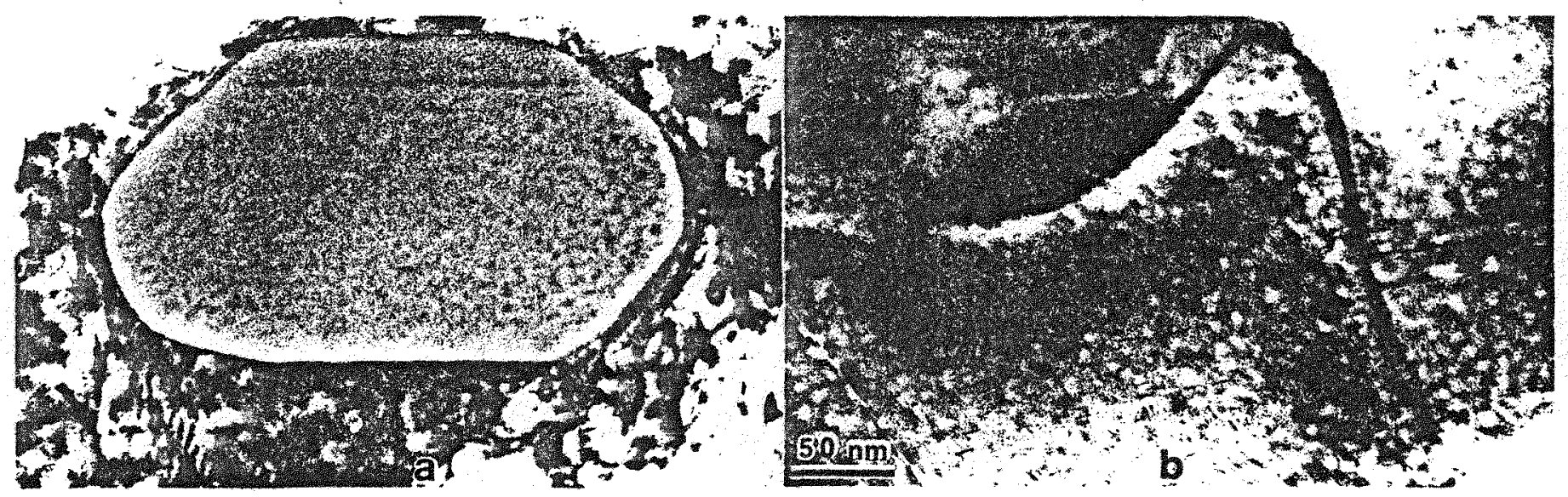

Figure 7.9.4. Irradiation induced substructure in $\mathrm{M}_{23} \mathrm{C}_{6}$ precipitate particles after irradiation in HFIR-CTR-30 to $39 \mathrm{dpa}$ at 300 and $600^{\circ} \mathrm{C}$. 
irradiation at $300^{\circ} \mathrm{C}$ and on the order of $11 \mathrm{~nm}$ after irradiation at $600^{\circ} \mathrm{C}$. Further work wil1 be needed to characterize this response more completely but is is apparent that such structural changes may result in mechanical properties changes.

$\underline{E B R-I I / A D-2}$

Specimens of HT-9 heat 91354 irradiated to 29 dpa in EBR-II were found to be very similar to specimens

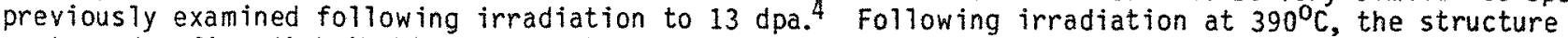
contained a fine distribution of small particles, a moderate density of perfect loops within dislocation tangles and well developed subgrain structure. Following irradiation at $500^{\circ} \mathrm{C}$, the precipitate density was drastically reduced and loop structure was not present. Only minor evidence of precipjtate coarsening was found.

Examples of these structures are given in Figure 7.9.5. Figures 7.9.5a and $\mathrm{c}$ show specimen $2 \mathrm{HCP}$ irradiated at $390^{\circ} \mathrm{C}$ to $29 \mathrm{dpa}$ at low and higher magnification. A typical lath structure can be seen at low magnification. Lath boundaries are decorated with elongated (plate-like) $M_{23} C_{6}$ precipitate and within the laths radiation-induced precipitate and dislocation structures are present. ${ }^{23}$ The precipitate and dislocation structures are shown at higher magnification in Figure $7.9 .5 \mathrm{c}$ using $\mathrm{g}=110$ contrast. The largest loops are on the order of $50 \mathrm{~nm}$ in diameter and precipitate particles are on the order of $10 \mathrm{~nm}$. Therefore, both dislocation loops and precipitates had grown as a result of further irradiation from 13 to $29 \mathrm{dpa}$. Cursory examination of $M_{23} C_{6}$ precipitate particies reveajed substructure similar to that shown in Figure 7.9.4.

Figures $7.9 .5 \mathrm{~b}$ and $\mathrm{d}$ show specimen $2 \mathrm{HCU}$ irradiated at $500^{\circ} \mathrm{C}$ to $29 \mathrm{dpa}$ at $70 \mathrm{w}$ and higher magnifications. The subgrain boundaries are well defined but subgrains are quite clean with only a few dislocations and small precipitates (possibly carbides) within subgrains. Evidence was found for helium bubble formation at subgra in boundaries. Bubbles were about the same size but the number density was much lower than for specimen SA23.

\section{Void Swelling Measurements}

Three areas of specimen SA21 irradiated at $400^{\circ} \mathrm{C}$ to 39 dpa were selected for quantitative void swelling measurements. All areas contained relatively high densities of voids so it can be assumed that they represent behavior approaching steady state with regard to void density levels. However, the measurements are expected to represent an extreme overestimate of the overall swelling in the specimen

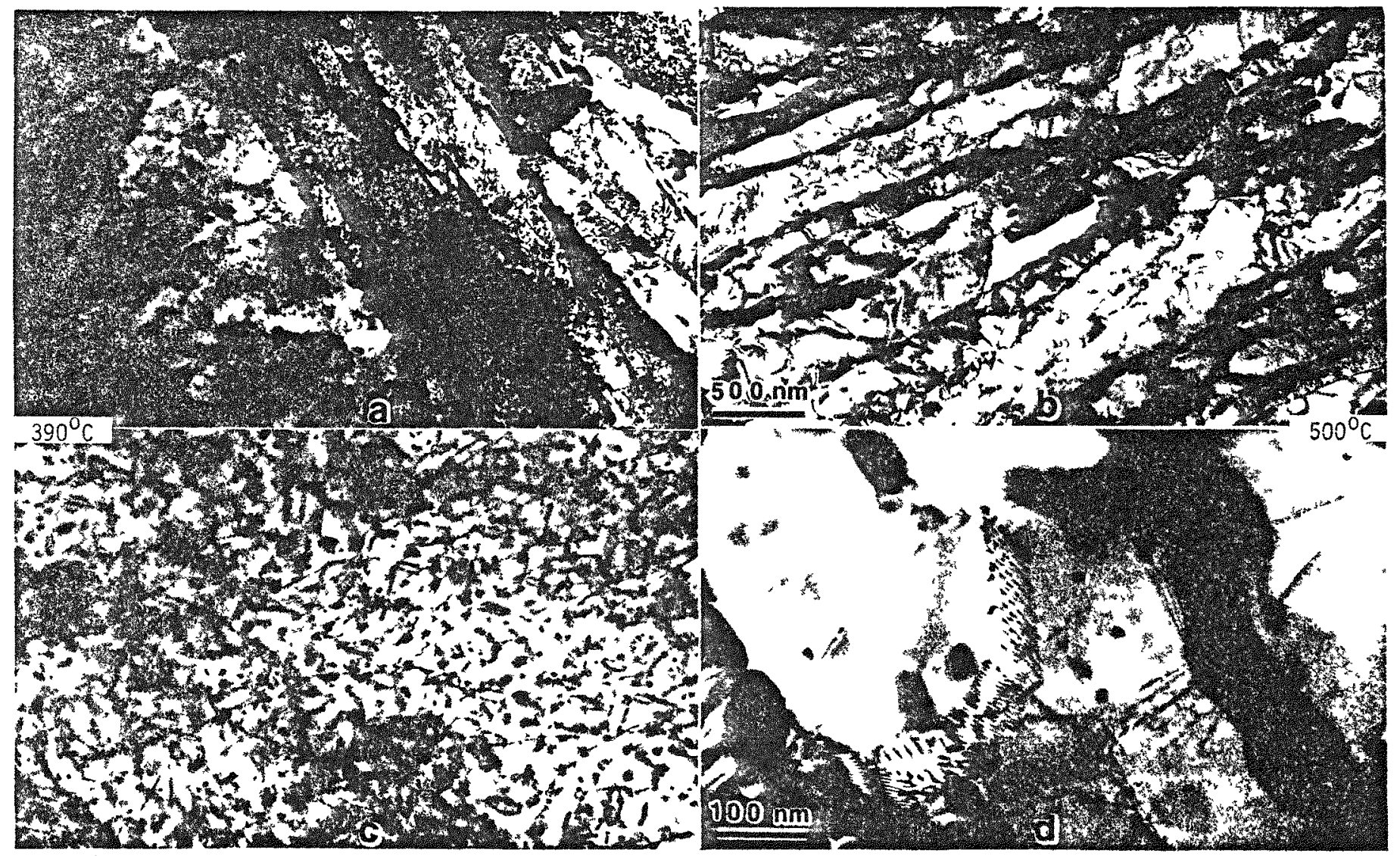

Figure 7.9.5. Microstructures for HT-9 specimens irradiated in EBRII-AD-2 to 29 dpa at low and moderate magnifications. 
because many much larger regions contained no voids. The void swelling varied between 0.035 and $0.050 \%$ with an average of $0.044 \%$. The void density varied between $5.1 \times 10^{14}$ and $8.4 \times 10^{14} \mathrm{~cm}^{-3}$ and the mean void size was in the range 10.8 to $11.7 \mathrm{~nm}$. (These measurements excluded features which were characterized as spherical helium bubbles.)

\subsubsection{Discussion}

Several topics for discussion arise from the present work. HT-9 is confirmed to swell as a result of irradiation in HFIR and the behavior can be attributed to the helium produced during irradiation in HFIR as opposed to a heat-to-heat effect. This result not only has implications regarding the fundamental consequences of helium production but also regarding swelling design equation development and heat-to-heat variability on swelling uncertainty predictions. Also, other microstructural changes were found as a result of further irradiation which have bearing on interpretation of fracture toughness measurements.

\section{Helium Effects on Swelling in Ferritics}

The present effort appears to show that the swelling response of HT-9 is different in EBR-II and HFIR. Following irradiation in HFIR to 39 dpa at $400^{\circ} \mathrm{C}$, cavitation typical of void swelling in the incubation regime was found whereas following irradiation in EBR-II to $29 \mathrm{dpa}$ at $390^{\circ} \mathrm{C}$, specimens of the same heat of material showed no evidence of void swelling. It has been noted that the preirradiation microstructures of the specimens for the two different tests were quite different. Therefore, three possible explanations for the different swelling response must still be considered: heat treatment procedure, fluence, and helium production. Heat-to-heat variations can be eliminated.

The preirradiation microstructure of HT-9 specimens irradiated in HFIR-CTR-30, 31, and 32 was atypical due to the absence of martensite lath structure decorated with $M_{23} C_{6}$ and due to the presence of excessively large carbide structure. It is possible that a consequence of this atypical heat treatment is enhanced swelling. However, this is considered unlikely. It has been proposed that the swelling resistance of HT-g arises from G-phase precipitation in-reactor. 4 The specimens of HT-9 heat 91354 did indeed contain G-phase following irradiation and therefore it is apparent that swelling resistance does not simply arise from the presence of G-phase. The mechanism is more complex; either G-phase dilutes the potency of gas atoms thereby preventing void nucleation or else high levels of helium production can overcome the swelling inhibition promoted by G-phase.

There are differences in accumulated dose; the specimens which swelled were irradiated to approximately $30 \%$ higher dose. However, it is unlikely that dose differences can explain the differençes in behavior. HT-9 has been irradiated in EBR-II to $75 \mathrm{dpa}$ and the swelling resistance was maintained. ${ }^{2}$ different heat was involved, but the present effort supports the contention that heat-to-heat differences are unimportant. The most likely explanation for the loss of swelling resistance in HFIR for two heats of HT-9 is that helium production promotes void swelling. Note that helium production in the HFIR irradiated specimens was 115 appm He $\mathrm{H}^{6}$ whereas in EBR-II it was on the order of 3 appm He.

The mechanism whereby helium promotes void swelling has received attention using both simulation and theoretical analysis techniques. It has been shown that for ferritic alloys irradiation with helium in conjunction with other ion species produces more swelling than when helium is not included. 7,8 Theoretical analyses 9,10 provide explanation based on the concept that a critical cavity size is needed before cavities can grow as voids and that helium additions promote large cavity sizes. Therefore, larger helium additions promote the onset of void swelling at lower fluences and tend to produce higher void densities. The concept of a critical cavity size has been considered experimentally for austenitic stajnless steels 10,11 and for an Fe-10Cr binary alloy preinjected with helium and subsequently ion bombarded. ${ }^{12}$ The present effort provides the following experimental observations with regard to critical cavity size in neutron irradiated ferritics. At $300^{\circ} \mathrm{C}$ in an HFIR environment, the critical cavity size is greater than $1.6 \mathrm{~nm}$. At $400^{\circ} \mathrm{C}$, the critical cavity size is on the order of $3.0 \mathrm{~nm}$ and at 500 and $600^{\circ} \mathrm{C}$, the critical cavity size is greater than $4 \mathrm{~nm}$ and $10 \mathrm{~nm}$, respectively. These values are based on helium bubble measurements, and it is not clear that bubbles located on grain boundaries and dislocations can indeed be sites for void growth. Nonetheless, these estimates are most relevant for theoretical analysis.

\section{HT-9 Swelling Design Equation for Fusion}

An approach to develop swelling equations for ferritic alloys has been proposed 13 and used to predict swelling in 2-1/4Cr-1Mo.14 The same approach can be used to predict swelling for HT-9 in a fusion environment. The key parameters for such an equation would be 1) a peak swelling rate of $0.06 \% / d p a, 2 /$ a peak swelling temperature at $400^{\circ} \mathrm{C}$ with negligible accumulated swelling to high fluence at 325 and $475^{\circ} \mathrm{C}$, and 3) an incubation parameter which defines the onset of steady state swelling (as a bilinear inflection point). A design equation for HT-9 has been included in the MHFES ${ }^{15}$ which defines the minimum incubation parameter arbitrarily as 72 .

The present results provide further insight regarding the selection of the minimum incubation parameter. Voids first appear in HT-9 between 20 and 39 dpa as a result of irradiation in HFIR. Helium generation in HT-9 irradiated in HFIR is approximately $25 \%$ of that expected in a fusion machine first wall. 6 Based on the concept of critivcal cavity size, it can be assumed that void formation will occur in a fusion environment at doses between 5 and $9 \mathrm{dpa}$. However, the first appearance of voids rarely corresponds to the void incubation dose. The incubation dose is gften two to three times longer, and in the case of ferritics, it may be signifjcantiy longer than that. 13 However, 72 dpa could well be an overestimate. 
Interpretation of Toughness Measurements

The large shifts in ductile-brittle transition-temperature (DBTT) following irradiation at about $400^{\circ} \mathrm{C}$ are found to saturate with increasing fluence. 16 This behavior could be traced to saturation in hardness increases due to irradiation (in fact a slight softening was found with further irradiation). 17 The present results indicate that irradiation-induced microstructural features such as dislocations and precipitates grow with increasing fluence. Precipitate growth is probably in part a result of coarsening. Therefore, the saturation of DBTT shifts can be ascribed to saturation of the irradiation-induced precipitate microstructures. Furthermore, further large shifts in DBTT with increasing fluence should not be expected.

\section{9 .5 Conclusions}

Microstructural examinations on a series of specimens of HT-9 heat 91354 have been performed in order to determine the effect of spectrum and additional dose on microstructural evolution during irradiation. The following conclusions can be made:

The major difference between EBR-II and HFIR irradiation is the appearance of cavities in al1 specimens irradiated in HFIR whereas cavities were generally not found in specimens irradiated in EBR-II. Cavities typical of helium bubbles were found following HFIR irradiation at 400,500 and $600^{\circ} \mathrm{C}$ and evidence for helium bubbles were found following HFIR irradiations at $300^{\circ} \mathrm{C}$. Void swelling typical of incubation response was found following irradiation at $400^{\circ} \mathrm{C}$. (Cavities typical of helium bubble formation were found following EBR-II irradiation at $500^{\circ} \mathrm{C}$.) The void swelling differences due to irradiation environment are attributed to helium generation; heat-to-heat variations can be ruled out.

Irradiation to increased dose does not significantly alter other wicrostructural features in either reactor spectrum. The major effect of increased dose was growth of the microstructural features, on the order of a doubling in size when the dose was effectively squared $\left(d \propto(\phi t){ }^{1 / 2}\right)$.

\subsubsection{Future Work}

This work will be continued.

\section{9 .7 References}

1. J. M. Vitek and R. L. Klueh "Microstructure of $9 \mathrm{Cr}-1$ MoVNb and $12 \mathrm{Cr}-1$ MoVW Ferritic Steels After Irradiation at Elevated Temperatures in HFIR" p. 108 in Alloy Development for Irradiation Performance Semiannual Progress Report for Period Ending September 30, 1983, D0E/ER-0045/11, 0ak Ridge National Laboratory, Oak Ridge, TN.

2. D. S. Gelles and L. E. Thomas "Effects of Neutron Irradiation on Microstructure in Experimental and Commercial Ferritic Alloys" p. 559 in Proceedings of Topical Conference on Ferritic Alloys for Use in Nuclear Energy Technologies, ed. J. W. Davis and D. J. Michel (The Metallurgical Society of AIME), Warrendale, PA, 1984.

3. Alloy Development for Irradiation Performance Program Review Meeting, November 9-10, 1983 at Chicago, IL.

4. D. S. Gelles and L. E. Thomas "Microstructural Examination of HT-9 and 9Cr-1Mo Contained in the AD-2 Experiment" p. 343 in Alloy Development for Irradiation Performance Semiannual Progress Report for Period Ending March 31, 1982, D0E/ER-0045/8, 0ak Ridge NationaT Laboratory, 0ak Ridge, TN.

5. D. S. Gelles and L. E. Thomas "Microstructural Examination of HT-9 Irradiated in the HFIR-CTR-32 Experiment" p. 162 in Alloy Development for Irradiation Performance Semiannual Progress Report for Period Ending September 30, 1982, D0E/ER-0045/9, Dak Ridge National Laboratory, Oak Ridge, TN.

6. L. R. Greenwood "Fission Reactor Dosimetry - HFIR-CTR 3036, 40" D. 5 in Damage Analys is and Fundamental Studies Quarterly Progress Report for Period Ending March 1985 , DOE/ER-0046/21, U.S. Department of Energy, Washington, DC.

7. G. Ayrauit "Cavity Formation in Single- and Dual-Ion Irradiated HT-9 and HT-9 + 2 Ni Ferritic Alloys" p. 182 in Damage Analys is and Fundamental Studies Quarterly Progress Report for Period Ending December 31, 1981, DOE/ER-0046/8, U.S. Department of Energy, Washington, DC.

8. L. L. Horton and J. Bentley "Swelling Behavior of a Simple Ferritic Alloy" p. 569 in Proceedings of Topical Conference on Ferritic Alloys for Use in Nuclear Energy Technologies, eds. J. W. Davis and D. J. Miche? (AIME), WarrendaTe, PA, 1984.

9. J. R. Townsend "Critical Cavity Sizes in Dual-Ion Bombarded 304 SS, Part II: Theoretical", J. Nucl. Matl., 108 and 109, 544, (1982). 
10. Section 6 "Radiation Effects - Helium" in the Proceedings of the Third Topical Metting on Fusion Reactor Materials, J. Nucl. Mat I., 122 and 123, 487, (1984).

11. J. A. Spitznage1, W. J. Choyke, W. J. Doyle, R. B. Irwin, J. R. Townsend and J. N. McGruer, "Critical Cavity Sizes in Dual-Ion Bombarded 304 SS, Part I: Experiment," 3. Nucl. Mat1., 108 and 109, 537, (1982).

12. L. L. Horton "Experimental Determination of the Critical Cavity Radius in Fe-10\% Cr for Ion Irradiation" p. 148 in Damage Analysis and Fundamental Studies Quarteriy Progress Report for period Ending September 1984, DOE/ER-0046/19, U.S. Department of Energy, Washington, DC.

13. D. S. Gelles and R. L. Meinecke "Swelling in Simple Ferritic Alloys Irradiated to High Fluence" p. 103 in A1loy Development for Irradiation Performance Semiannual Progress Report for Period Ending September 30, 1983, D0E/ER-0045/11, Oak Ridge National Laboratory, Oak Ridge, IN.

14. D. S. Gelles and R. J. Puigh "Evaluation of Ferritic Alloy Fe 2-1/4Cr-1Mo After Neutron Irradiation Irradiation creep and Swelling" ibid. 82.

15. File Code AA01-3304 (E-1) Supplement Package 10, Materials Handbook for Fusion Energy Systems, DOE/TIC-10122.

16. W. L. Hu "Charpy Impact Test Results of Ferritic Alloys at a Fluence of $6 \times 10^{22} \mathrm{n} / \mathrm{cm}^{2}$ ", $\mathrm{p} .106$ in Alloy Development for Irradiation Performance Semiannual Progress Report for Per iod Ending September 30, 1984, DOE/ER-0045/13, Oak Ridge National Laboratory, Dak Ridge, TN.

17. D. S. Gel]ęs and W. L. Hu "Fractographic Examination of Ferritic Alloy Charpy Specimens at a Fluence of $6 \times 10^{22} \mathrm{n} / \mathrm{cm}^{2 n}$ this report. 